\title{
Paracoccus onubensis sp. nov., a novel alphaproteobacterium isolated from the wall of a show cave
}

\author{
Sara Gutierrez-Patricio', Jose L. Gonzalez-Pimentel², Ana Zelia Miller ${ }^{1,2}$, Bernardo Hermosin¹, Cesareo Saiz-Jimenez ${ }^{1}$ \\ and Valme Jurado ${ }^{1, *}$
}

\begin{abstract}
A novel facultatively anaerobic, non-motile, Gram-stain-negative, non-endospore-forming alphaproteobacterium, strain 1011 MAR3C25 $5^{\top}$, was isolated from a white biofilm colonizing the walls of the Andalusian show cave Gruta de las Maravillas (Huelva, Spain). Strain $1011 \mathrm{MAR} 3 \mathrm{C} 25^{\top}$ grew at $8-42^{\circ} \mathrm{C}$ (optimum, $20-30^{\circ} \mathrm{C}$ ), at pH 5.0-9.0 (optimum, pH 5.0-6.0) and in the presence of $0-12 \%(w / v) ~ N a C l ~(o p t i m u m ~ 3-5 \%)$. Cells were catalase- and oxidase-positive. The strain grew heterotrophically with various carbon sources and chemoautotrophically with thiosulfate under aerobic conditions. Results of phylogenetic analysis showed that strain 1011MAR3C25 ${ }^{\top}$ was related to Paracoccus saliphilus DSM $18447^{\top}$ and Paracoccus alkanivorans LMG $30882^{\top}(97.90 \%$ and $97.32 \% 16$ S rRNA sequence identity values, respectively). The major respiratory quinone was ubiquinone Q-10 and the predominant fatty acid was $\mathrm{C}_{18: 1} \omega 7 \mathrm{c}$. The polar lipid profile consisted of diphosphatidylglycerol, phosphatidylcholine, phosphatidylglycerol, an unidentified aminolipid, an unidentified glycolipid and an unidentified polar lipid. The DNA G+C content was $60.3 \mathrm{~mol} \%$. Based on a polyphasic taxonomic study it is proposed that strain 1011 MAR3C25 $\left(=C E C T\right.$ 9092 ${ }^{\top}=L M G ~ 29414^{\top}$ ) represents a novel species of the genus Paracoccus, for which the name Paracoccus onubensis sp. nov. is proposed.
\end{abstract}

The genus Paracoccus belongs to the class Alphaproteobacteria and family Rhodobacteraceae. It was described by Davis et al. [1] with Paracoccus denitrificans as the type species. Members of this genus are Gram-stain-negative, non-spore-forming, usually non-motile, and catalase- and oxidase-positive. The major cellular fatty acid is $\mathrm{C}_{18: 1} \omega 7 \mathrm{c}$. The $\mathrm{G}+\mathrm{C}$ content of the DNA is $64-70 \%$ mol. Currently the genus Paracoccus includes 74 validly named species and 15 non-validly named species (https://lpsn.dsmz.de/genus/ paracoccus). The general model of metabolism is chemoorganotrophic. Some species are able to grow as facultative chemolithoautotrophs using reduced sulphur compounds as substrates and others can live as facultative methylotrophs using methanol as a substrate [2]. Paracocci are ubiquitous and growth occurs in water [3] and soil [4-6], among other environments [7]. Paracoccus cavernae was isolated from a cave air [8]. In this study, a bacterial strain, 1011MAR3C25, was isolated from white biofilms coating the walls of a cave and characterized using a polyphasic approach to determine its taxonomic position. Strain 1011MAR3C $25^{\mathrm{T}}$ is proposed to represent a novel species within the genus Paracoccus named Paracoccus onubensis sp. nov.

\section{ISOLATION AND ECOLOGY}

Strain 1011MAR3C25 $5^{\mathrm{T}}$ was isolated from white biofilms coating the walls of Gruta de las Maravillas ( $37^{\circ} 53^{\prime} 27.92^{\prime \prime}$ $\left.\mathrm{N}, 6^{\circ} 33^{\prime} 57.25^{\prime \prime} \mathrm{E}\right)$. Gruta de las Maravillas is a cave located in Southwestern Spain. This was the first show cave open to tourism, in 1914. Its length is $2130 \mathrm{~m}$ from which around $1400 \mathrm{~m}$ are visited. Along the tourist trail, small, round, white-coloured colonies forming biofilms on the walls can be observed, which are particularly abundant close to the cave exit. White cave biofilms are composed of a large diversity of uncultured representatives of many different major evolutionary lineages $[9,10]$; therefore, they represent an important source of novel bacteria. In October 2011, samples were obtained aseptically by scraping off the white-coloured colonies with a sterile scalpel, stored in sterile tubes at $5^{\circ} \mathrm{C}$, and analysed immediately upon arrival in the laboratory.

Author affiliations: 'Instituto de Recursos Naturales y Agrobiologia, IRNAS-CSIC, Avenida Reina Mercedes 10, 41012 Sevilla, Spain; ${ }^{2}$ HERCULES Laboratory, Evora University, Largo Marquês de Marialva 8, 7000-809, Évora, Portugal.

${ }^{*}$ Correspondence: Valme Jurado, vjurado@irnase.csic.es

Keywords: Paracoccus; Proteobacteria; show cave; whole genome average nucleotide identity.

Abbreviations: ANI, average nucleotide identity; DDH, DNA-DNA hybridization; EBS, E-basal salts.

The GenBank/EMBL/DDBJ accession numbers for the genome and 16S rRNA gene sequences of strain 1011 MAR3C25 $5^{\top}$ are QZCG00000000 and LN867136, respectively.

One supplementary table and four supplementary figures are available with the online version of this article.

$004942 \odot 2021$ The Authors 
The samples were resuspended in a sterile $0.85 \%(\mathrm{w} / \mathrm{v}) \mathrm{NaCl}$ solution and subsequently seeded in a 10-fold diluted marine agar medium (Difco). Strain 1011MAR3C25 $5^{\mathrm{T}}$ was isolated on marine agar after incubation at $30^{\circ} \mathrm{C}$ for 7 days.

\section{PHYLOGENY}

Genomic DNA was extracted according to Marmur [11]. The $16 \mathrm{~S}$ rRNA genes were amplified following the method described by Jurado et al. [12]. The identification of phylogenetic neighbours was determined using the global alignment algorithm on the EzTaxon-e database [13]. The phylogenetic analyses were carried out by aligning and comparing the nearly complete $16 \mathrm{~S}$ rRNA gene sequence of strain $1011 \mathrm{MAR} 3 \mathrm{C} 25^{\mathrm{T}}$ with corresponding sequences of members of the genus Paracoccus. In addition, to find more precise phylogenetic relationships of the species closest to strain 1011MAR3C25 $5^{\mathrm{T}}$, phylogenomic treeing based on 139 single-copy genes was performed according to Campbell et al. [14]. Alignments were created using the multiple sequence alignment program MUSCLE [15]. Phylogenetic trees were reconstructed using the best substitution model selected by the software MEGA X [16]. The evolutionary history using the $16 \mathrm{~S} r R N A$ gene sequences was inferred by using the maximumlikelihood method, Kimura's two-parameter model with a discrete Gamma distribution and invariant sites [17]. The evolutionary history of the concatenated genes was deduced using the maximum-likelihood method and the general time reversible model with a discrete gamma distribution and invariant sites [18]. The robustness of the tree was evaluated by bootstrap resampling (1680 replicates).

Sequencing of its $16 \mathrm{~S}$ rRNA gene revealed that strain 1011MAR3C25 $5^{\mathrm{T}}$ belonged to the genus Paracoccus. The results of phylogenetic analysis based on 16S rRNA gene sequences showed that strain $1011 \mathrm{MAR} 3 \mathrm{C} 25^{\mathrm{T}}$ was closely related to Paracoccus saliphilus DSM $18447^{\mathrm{T}}$, Paracoccus alkanivorans LMG 30882 ${ }^{\mathrm{T}}$, 'Paracoccus siganidrum' DSM 26381 ${ }^{\mathrm{T}}$, Paracoccus homiensis DSM $17862^{\mathrm{T}}$ and Paracoccus aestuarii DSM $19484^{\mathrm{T}}$, with identity values of 97.90, 97.32, 97.18, 96.96 and 96.96\%, respectively. Besides, the phylogenetic trees showed that the closest relatives of strain $1011 \mathrm{MAR} 3 \mathrm{C} 25^{\mathrm{T}}$ were $P$. saliphilus and $P$. alkanivorans (Figs 1, S1 and S2, available in the online version of this article) and were separated from the rest of the species within the genus Paracoccus. In the phylogenetic trees based on 16S rRNA gene sequences (Figs 1 and S1), the nodes were well-supported with bootstrap values greater than 60 . The bootstrap value of 100 in the phylogenomic tree (Fig. S2) showed the high phylogenetic relatedness between strain 1011MAR3C25T, P. saliphilus and P. alkanivorans.

\section{GENOME FEATURES}

The genomic DNA of strain 1011MAR3C25 , P. aestuarii DSM $19484^{\mathrm{T}}$ and 'P. siganidrum' DSM $26381^{\mathrm{T}}$ were sequenced using $250 \mathrm{bp}$ paired-end reads on an Illumina HiSeq platform by means of a Nextera XT library prep kit. The read quality was checked with FastQC 0.11.5 (www.bioinformatics.babraham. ac.uk/projects/fastqc). Reads were adapter-trimmed using
Trimmomatic 0.36 with a sliding window quality cutoff of Q15 [19]. De novo assembly of this draft genome was performed using SPAdes 3.7 [20]. The remaining genomes of the reference strains were taken from public databases. Calculations of whole genome average nucleotide identity (ANI) and TETRA values were carried out using the JSpecies software [21], whereas OrthoANI measurements were calculated as described by Lee et al. [22]. Additionally, the genomic relationship between strain $1011 \mathrm{MAR} 3 \mathrm{C} 25^{\mathrm{T}}$ and its closest relatives was examined by classical DNA-DNA hybridization (DDH) as described by Urdiain et al. [23] and whole genome sequenced-based DDH predicted by the Genome-to-Genome Distance Calculator 2.1 (http://ggdc.dsmz.de) [24]. Gene prediction was carried out with Prodigal [25], whereas Sma3s [26] was implemented for functional annotations using the curated Uniprot-SwissProt database [27].

The relatedness between strain 1011MAR3C25 $5^{\mathrm{T}}$ and its phylogenetically closest type strains according to $16 \mathrm{~S}$ rRNA gene sequences was assessed by ANI, TETRA and OrthoANI calculations. The genome sizes and accession numbers of strain 1011MAR3C25 $5^{\mathrm{T}}$, P. aestuarii DSM $19484^{\mathrm{T}}$, 'P. siganidrum' DSM $26381^{\mathrm{T}}$ and $P$. alkanivorans LMG $30882^{\mathrm{T}}$ were $4764139 \mathrm{bp}$ (QZCG00000000), 3747355 bp (QZEV00000000), 4906790bp (QZEW00000000) and $4662693 \mathrm{bp}$ (QOKZ00000000), respectively. The genome of strain 1011 MAR3C $25^{\mathrm{T}}$ contained a total of 40 contigs. The N50 value was 272503, and the largest contig was $518150 \mathrm{bp}$. The average $\mathrm{G}+\mathrm{C}$ content was $60.3 \mathrm{~mol} \%$. A total of 4595 genes were detected, with three rRNA and 45 tRNA genes predicted and 4486 proteins (Table S1). Genome coverage was $30.0 \times$.

Strain 1011MAR3C25 showed ANI and OrthoANI values below $85 \%$ with the closest species of the genus Paracoccus (Table 1). Values ranging from 84.52 to $79.57 \%$ and from 84.67 to $80.10 \%$ were obtained for strain 1011MAR3C25 ${ }^{\mathrm{T}}$ and both $P$. saliphilus DSM $18447^{\mathrm{T}}$ and $P$. alkanivorans LMG $30882^{\mathrm{T}}$, respectively. Values below $85 \%$ are lower than the generally accepted species boundary $94-96 \%$ proposed by Richter and Rosselló-Móra [21]. Moreover, the TETRA values were less than 0.99 , supporting the ANI calculation and the species circumscription. The ANIb, ANIm, OrthoANI and TETRA results showed that strain $1011 \mathrm{MAR} 3 \mathrm{C} 25^{\mathrm{T}}$ should be classified as a novel member of the genus Paracoccus.

DDH values among strain 1011MAR3C25 $5^{\mathrm{T}}$ and $P$. saliphilus DSM $18447^{\mathrm{T}}$, P. aestuarii DSM $19484^{\mathrm{T}}$, $P$. homiensis DSM $17862^{\mathrm{T}}$, P. alkanivorans LMG $30882^{\mathrm{T}}$ and 'P. siganidrum' DSM $26381^{\mathrm{T}}$ were between $42.17-49.84 \%$ for classical DDH, and $20.40-23.70 \%$ for in silico DDH (Table 1). In both analyses, the percentages were below the recommended cutoff point of $70 \% \mathrm{DDH}$ for species delineation and, therefore, indicated that strain 1011MAR3C25 ${ }^{\mathrm{T}}$ was not related at the species level with any of the five studied type strains.

Predicted and annotated genes with Prodigal and Sma3s were grouped according to the biological processes classified in the UniProt database (Fig. S3). Genes involved in the transport category were the most represented in strain 1011MAR3C25 $5^{\mathrm{T}}$, 


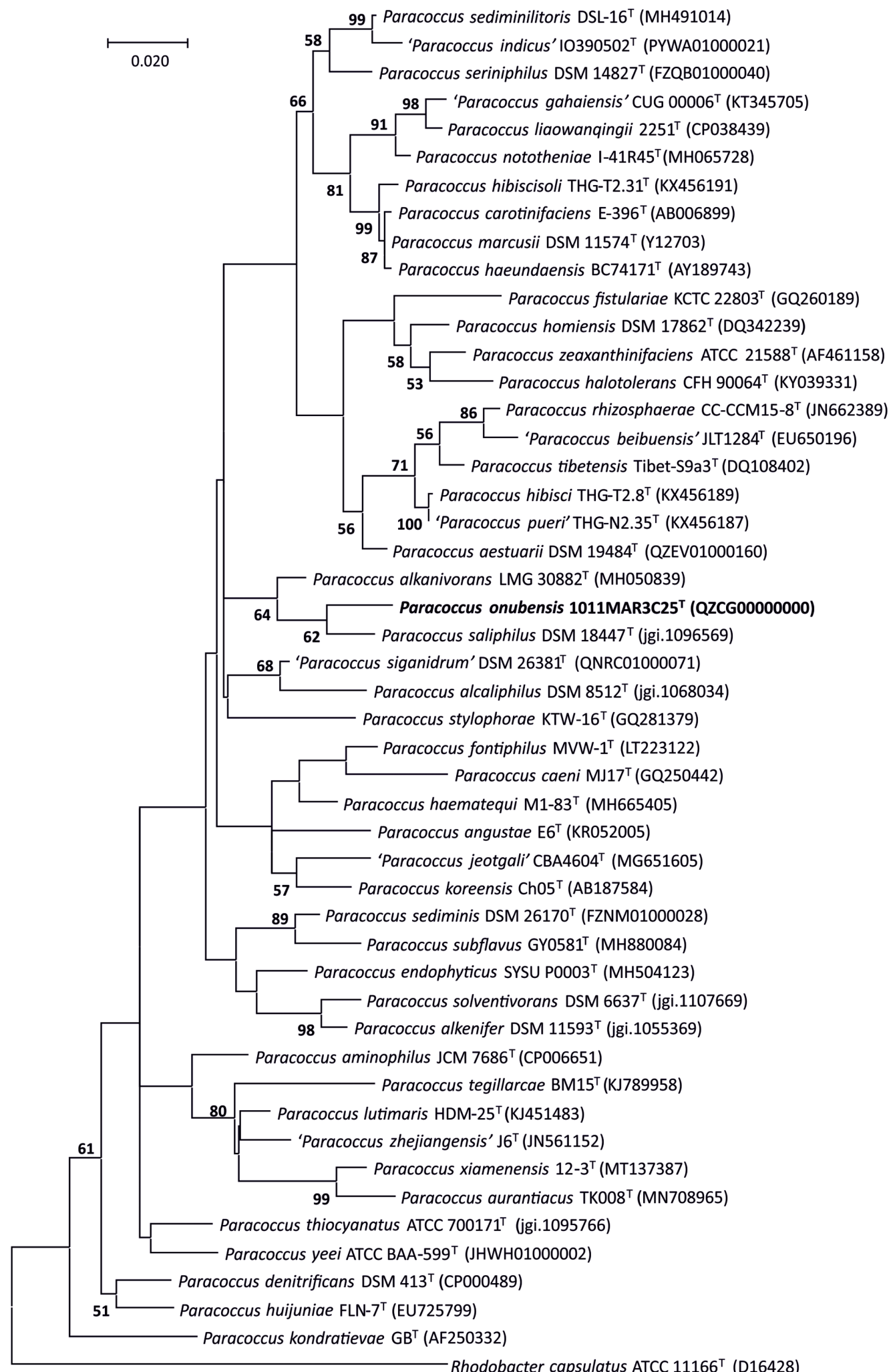

Rhodobacter capsulatus ATCC $11166^{\top}$ (D16428)

Fig. 1. Maximum-likelihood phylogenetic tree based on $16 \mathrm{~S}$ rRNA gene sequences showing the relationship of strain $1011 \mathrm{MAR} 3 \mathrm{C} 25^{\mathrm{T}}$ with other species of the genus Paracococcus. Bootstrap values (>50\%) are expressed as percentages of 1680 replicates. There were a total of 1418 positions in the final dataset. The $16 \mathrm{~S}$ rRNA gene sequence of Rhodobacter capsulatus ATCC $11166^{\top}$ (D16428) was used as an outgroup. Bar, 0.02 substitutions per nucleotide position. 
Table 1. Results of ANI calculations (\%), TETRA correlations and DDH values (\%) of strain 1011 MAR3C25 and other species of the genus Paracoccus Taxa: 1, 1011MAR3C25T (QZCG00000000); 2, P. saliphilus (FTOU00000000); 3, 'P. siganidrum' (QNRC00000000); 4, P. homiensis (F0H000000000); 5, P. aestuarii (QZEV00000000); 6, P. alkanivorans (QOKZ00000000). ND, Not determined, - duplicate data

\begin{tabular}{|c|c|c|c|c|c|c|}
\hline & 1 & 2 & 3 & 4 & 5 & 6 \\
\hline 2 & 78.03 & 100 & 76.63 & 75.86 & 74.71 & 84.70 \\
\hline 3 & 76.25 & 77.28 & 100 & 77.23 & 78.14 & 77.88 \\
\hline 5 & 74.63 & 75.57 & 78.68 & 76.76 & 100 & 76.02 \\
\hline 6 & 78.81 & 84.86 & 77.24 & 76.22 & 75.41 & 100 \\
\hline \multicolumn{7}{|l|}{ ANIm } \\
\hline 1 & 100 & 84.53 & 83.79 & 83.39 & 83.50 & 84.66 \\
\hline 4 & 83.39 & 83.77 & 84.39 & 100 & 84.20 & 83.87 \\
\hline 5 & 83.52 & 83.43 & 84.70 & 84.21 & 100 & 83.76 \\
\hline 6 & 84.67 & 87.87 & 84.31 & 83.87 & 83.76 & 100 \\
\hline \multicolumn{7}{|l|}{ OrthoANI } \\
\hline 1 & 100 & - & - & - & - & - \\
\hline 2 & 79.57 & 100 & - & - & - & - \\
\hline 3 & 77.33 & 78.78 & 100 & - & - & - \\
\hline 4 & 76.51 & 77.94 & 78.77 & 100 & - & - \\
\hline 3 & 0.75838 & 0.86604 & - & - & - & - \\
\hline 4 & 0.85423 & 0.89725 & 0.88234 & - & - & - \\
\hline 5 & 0.69568 & 0.81374 & 0.93282 & 0.90284 & - & - \\
\hline 6 & 0.961 & 0.98794 & 0.85662 & 0.89001 & 0.80492 & - \\
\hline WGS-based DDH & 100 & 23.20 & 21.40 & 20.40 & 20.40 & 23.70 \\
\hline Classical DDH value & 100 & 49.84 & 42.17 & 44.14 & 46.56 & ND \\
\hline
\end{tabular}

with $22.22 \%$ of the total. This category includes the movement of ions, molecules, complexes and organelles into, out of or within the bacterium through agents such as transporters, pores or motor protein.

In silico analysis for the genome annotation of strain 1011MAR3C25 $5^{\mathrm{T}}$ confirmed the in vivo physiological studies detailed below for nitrogen and carbon metabolism. Thus, the assimilation of nitrate and urea was confirmed after the prediction of nas $A D$ and ureABCDEFG genes in the genome, respectively, as well as the presence of mechanisms for the assimilation of inorganic carbon, such as the $\mathrm{CO}_{2}$ fixation process, through the presence of ribulose bisphosphate carboxylase large chain $(c b b L)$ and the ribulose bisphosphate carboxylase small subunit ( $c b b S$ ), among others.

Of interest, the annotated genome of strain 1011MAR3C25 ${ }^{\mathrm{T}}$ suggested the presence of genes involved in the synthesis 
of the flagellum, with the presence of five genes, flh $G H I$ and fliIP, which contrasted with the in vivo analyses where no motility was observed. These annotations could be also related to the stress response and virulence factors in this bacterium being part of these biological processes.

\section{PHYSIOLOGY AND CHEMOTAXONOMY}

The investigation of morphological, chemotaxonomic and physiological characteristics of strain $1011 \mathrm{MAR} 3 \mathrm{C} 25^{\mathrm{T}}$ and its phylogenetically closest strains, P. saliphilus DSM $18447^{\mathrm{T}}$, 'P. siganidrum' DSM 26381' $P$. homiensis DSM $17862^{\mathrm{T}}$ and P. aestuarii DSM $19484^{\mathrm{T}}$ was performed in triplicate on marine agar medium at $30^{\circ} \mathrm{C}$, unless otherwise indicated.

Cell morphology and dimensions were examined in a Zeiss Axioscope two phase-contrast microscope equipped with image-analysing Axio Vision 2.05 software, and by field emission scanning electron microscopy (FESEM). For FESEM observations, the biomass was collected from the agar surface and fixed with $2.5 \%$ glutaraldehyde in $0.1 \mathrm{M}$ cacodylate buffer ( $\mathrm{pH} 7.4$ ) at $4{ }^{\circ} \mathrm{C}$ for $2 \mathrm{~h}$. The cells were separated from the mixture by centrifugation and washed twice in cacodylate buffer for $5 \mathrm{~min}$ each and post-fixed in $1 \%$ osmium tetroxide for $1 \mathrm{~h}$ at $4{ }^{\circ} \mathrm{C}$. After dehydration by subsequent dilution series in ethanol and acetone, the bacteria were dried in a critical point drying device (CPD 030 , Balzers) at $34.5^{\circ} \mathrm{C}$. Finally, the bacterial cells were sputter-coated with a thin gold-palladium film and examined in a JEOL JSM-7001F microscope. FESEM examinations were operated in secondary electron detection mode with an acceleration potential of $15 \mathrm{kV}$. Colony morphology was analysed using 3-5 days old cultures grown on marine agar medium utilizing a stereo microscope. Motility was examined on nutrient broth or marine broth media containing $0.3 \%$ agar [28] and confirmed by staining with flagella stain droppers (BD; according to the manufacturer's instructions) and observation in a phase contrast microscope. Oxidase activity was tested by monitoring the oxidation on BBL DrySlide Oxidase (BD). Catalase activity was determined by the production of bubbles after addition of a drop of $3 \%(\mathrm{v} / \mathrm{v})$ hydrogen peroxide on cellular biomass smeared on a glass slide. Acid production from carbohydrates, assimilation tests and enzymatic activities were identified with the API 50CH, API 20NE and API ZYM galleries (bioMérieux), according to the manufacturer's instructions. The Gram reaction was performed following the method of Hucker [29] and was confirmed by $\mathrm{KOH}$-lysis test [30]. The temperature range for growth was tested at $3,4,8,10,15,20,25,30,37,40,42$ and $45^{\circ} \mathrm{C}$. Tolerance to $\mathrm{NaCl}$ was assessed on nutrient agar medium supplemented with $0,3,5,7,9,10,13,14,15$ and $16 \%$ $(\mathrm{w} / \mathrm{v}) \mathrm{NaCl}$. Growth at different $\mathrm{pH}$ values were assessed with marine broth adjusted to $\mathrm{pH} 3.0-13.0$ (at intervals of $1.0 \mathrm{pH}$ unit) by using the following buffer system: $\mathrm{pH}$ 3.0-5.0 with $0.1 \mathrm{M}$ citric acid/0.1 M sodium citrate; $\mathrm{pH}$ $6.0-8.0$ with $0.2 \mathrm{M}$ sodium phosphate dibasic/ $0.2 \mathrm{M}$ sodium phosphate monobasic; $\mathrm{pH}$ 9.0-11.0 with $0.1 \mathrm{M}$ sodium bicarbonate/0.1 M sodium carbonate; $\mathrm{pH}$ 12.0-13.0 with $0.2 \mathrm{M}$ potassium chloride/0.2 M sodium hydroxide. Negative controls were used to verify each buffer. Utilization of ammonium sulphate $\left(7.8 \mathrm{~g} \mathrm{l}^{-1}\right)$, sodium glutamate $(20 \mathrm{~g}$ $\left.\mathrm{l}^{-1}\right)$, sodium nitrate $\left(7.8 \mathrm{~g} \mathrm{l}^{-1}\right)$, casamino acids $\left(10 \mathrm{~g} \mathrm{l}^{-1}\right)$ and peptone $\left(10 \mathrm{~g} \mathrm{l}^{-1}\right)$ as sole nitrogen sources were tested in medium $\mathrm{N}$ (artificial seawater containing $1.0 \mathrm{~g}^{-1}$ glucose and $0.2 \mathrm{~g} \mathrm{l}^{-1} \mathrm{NaHCO} 3, \mathrm{pH} 7.0$ ) [31]. The oxygen requirement for bacterial growth was tested in anaerobic chambers (GENbag anaer, bioMérieux). Endospore production was tested on oatmeal agar (Difco), nutrient agar (Difco) and Bennett's agar media [32]. DNA and casein hydrolysis were tested by using DNAse test agar (Difco) and milk agar (Merck), respectively, according to Barrow and Feltham [33]. Lypolytic activity was examined in Tweens 20,40 and 80 [34]. In addition to chemoorganotrophic metabolism, strain $1011 \mathrm{MAR} 3 \mathrm{C} 25^{\mathrm{T}}$ was tested for chemolithoautotrophy and methylotrophy using reduced sulphur compounds: as thiosulphate and methanol, respectively. Strain $1011 \mathrm{MAR} 3 \mathrm{C} 25^{\mathrm{T}}$ was grown aerobically and anaerobically at $28^{\circ} \mathrm{C}$ in E-basal salts (EBS) [35], supplemented with agar $\left(15.00 \mathrm{~g} \mathrm{l}^{-1}\right)$ and $20 \mathrm{~mm}$ sodium thiosulfate [36]. Culture of strain $1011 \mathrm{MAR} 3 \mathrm{C} 25^{\mathrm{T}}$ on methanol $(50 \mathrm{~mm})$ was performed in a liquid medium [37]. As a control, EBS supplemented with glucose $\left(1.0 \mathrm{~g} \mathrm{l}^{-1}\right)$ was used. Cellular fatty acid profiles were analysed in triplicate after collecting biomass from a culture grown on trypticase soy broth agar for $72 \mathrm{~h}$ at $30^{\circ} \mathrm{C}$ following the methodology described by Jurado et al. [38]. Analyses of quinones and polar lipids were carried out by the Identification Service, LeibnizInstitut DSMZ (Deutsche Sammlug von Mikroorganismen und Zellkulturen GmbH, Braunschweig, Germany).

The results from the phylogenetic analysis and whole genome comparisons indicated that strain $1011 \mathrm{MAR} 3 \mathrm{C} 25^{\mathrm{T}}$ was different from the previously published type strains. Thus, morphological, physiological and biochemical analyses of strain 1011MAR3C25 $5^{\mathrm{T}}$ were only compared with the closest type strains: P. saliphilus DSM $18447^{\mathrm{T}}$, P. alkanivorans LMG $30882^{\mathrm{T}}$ and other Paracoccus species (Table 2).

Strain 1011MAR3C25 $5^{\mathrm{T}}$ and the reference strains had many differences (Table 2). These differences were mainly related to $\mathrm{NaCl}$ tolerance, temperature and $\mathrm{pH}$ conditions for growth, hydrolysis of Tweens 20 and 40, reduction of nitrate, growth on different substrates, enzymatic activity, and acid produced from different sugars.

Strain 1011MAR3C25 $5^{\mathrm{T}}$ tolerated concentrations of $0-12 \%$ $(\mathrm{w} / \mathrm{v}) \mathrm{NaCl}$, like P. homiensis DSM $17862^{\mathrm{T}}$, P. alkanivorans LMG $30882^{\mathrm{T}}$ and P. saliphilus DSM $18447^{\mathrm{T}}$. P. aestuarii DSM $19484^{\mathrm{T}}$ and 'P. siganidrum' DSM $26381^{\mathrm{T}}$ tolerated 5 and $10 \%(\mathrm{w} / \mathrm{v}) \mathrm{NaCl}$, respectively. Optimal growth conditions also differed from one species to another. All the studied strains grew up to a temperature of $42^{\circ} \mathrm{C}$, except $P$. saliphilus DSM $18447^{\mathrm{T}}$, which grew up at $37^{\circ} \mathrm{C}$. Only P. aestuarii DSM $19484^{\mathrm{T}}$ grew at $4^{\circ} \mathrm{C}$. All the studies strains grew within $\mathrm{pH} 5-8$; however, the $\mathrm{pH}$ optimum differed between them. Strain 1011MAR3C25 T, 'P. siganidrum' DSM $26381^{\mathrm{T}}$ and $P$. aestuarii DSM $19484^{\mathrm{T}}$ produced acid from 
Table 2. Differential characteristics of strain $1011 \mathrm{MAR} 3 \mathrm{C} 25^{\top}$ and its closest relatives

Strains: 1, 1011MAR3C25'; 2, Paracoccus saliphilus DSM 18447'; 3, 'Paracoccus siganidrum' DSM 26381'; 4, Paracoccus homiensis DSM 17862'; 5 , Paracoccus aestuarii DSM $19484^{\top}$; 6. Paracoccus alkanivorans LMG30882'. Results from this study were obtained from cells grown under the same conditions. All data from the present study unless otherwise indicated. +, Positive; -, negative; (+), weakly positive.

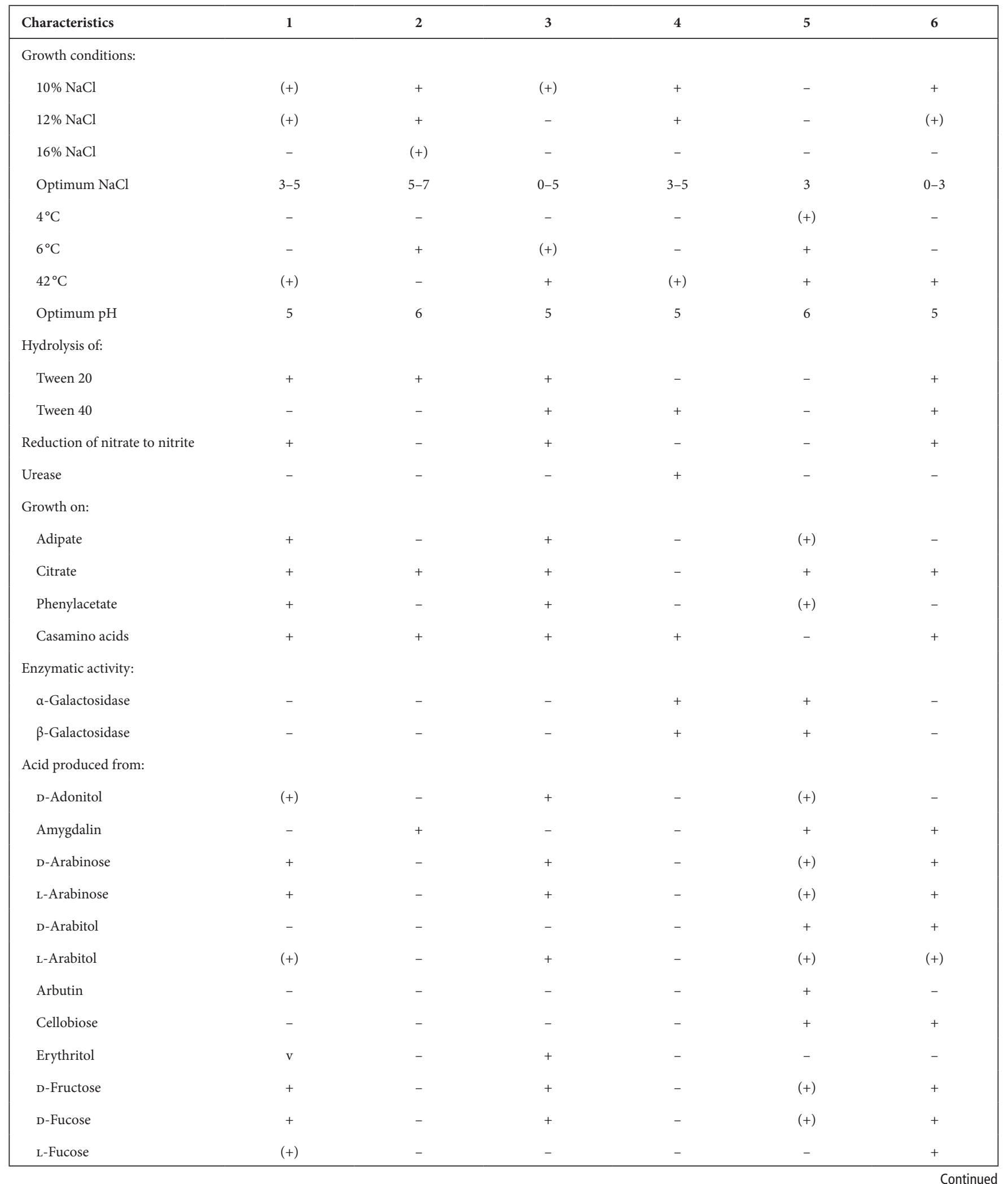


Table 2. Continued

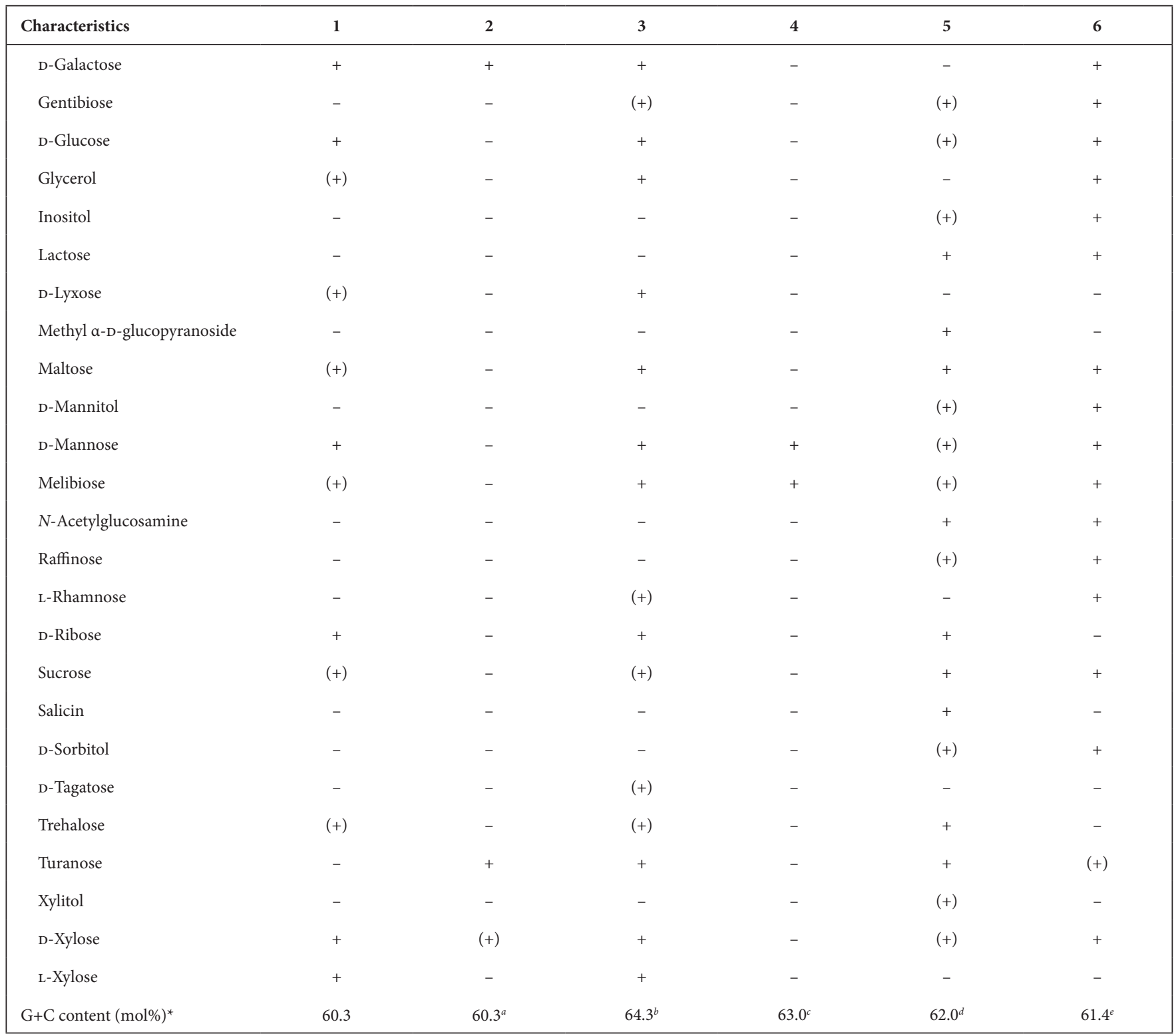

*a, Wang et al. [6]; b, Liu et al. [39]; c, Kim et al. [40]; d, Roh et al. [3]; e, Zhang et al. [41].

a greater number of sugars than P. saliphilus DSM $18447^{\mathrm{T}}$, P. alkanivorans LMG $30882^{\mathrm{T}}$ and $P$. homiensis DSM $17862^{\mathrm{T}}$.

All strains used sodium nitrate, ammonium sulphate, sodium glutamate and peptone as sole nitrogen sources. All strains, except $P$. aestuarii DSM $19484^{\mathrm{T}}$, used casamino acids. Strain 1011MAR3C25 $5^{\mathrm{T}}$ was able to oxidize thiosulfate but it did not grow anaerobically with this sulphur compound. Neither did it grow on methanol as an energy source. Strain 1011MAR3C25 had a fatty acid pattern similar to that of the genus Paracoccus [2] (Table 3). The most abundant fatty acid was $\mathrm{C}_{18: 1} \omega 7 \mathrm{c}$ (72.55\%), followed by others in minor proportions $\left(\mathrm{C}_{18: 0}\right.$, $\mathrm{C}_{19: 0}$ cyclo $\omega 8 c, \mathrm{C}_{16: 0^{\prime}}, \mathrm{C}_{14: 0} 3-\mathrm{OH}$ and/or $\mathrm{C}_{16: 1}$ iso I, $\mathrm{C}_{10: 0} 3-\mathrm{OH}$, $\left.\mathrm{C}_{17: 1} \omega 8 \mathrm{c}\right)$. The main difference from its closest reference strain was the presence of the fatty acid $\mathrm{C}_{17: 1} \omega 8 \mathrm{c}$ and the proportion of some others such as $\mathrm{C}_{16: 0^{\circ}}$. Strain 1011MAR3C25 contained ubiquinone-10 as the major respiratory quinone like other species of the genus Paracoccus. The composition of its polar lipids included diphosphatidylglycerol, phosphatidylcholine, phosphatidylglycerol, an unidentified aminolipid, an unidentified glycolipid and an unidentified polar lipid.

Based on the results of the phenotypic and genotypic analyses presented in this study, it is proposed that the alphaproteobacterium strain 1011 MAR3C25 $5^{\mathrm{T}}$ represents a novel species within the genus Paracoccus. We propose the name Paracoccus onubensis for strain 1011MAR3C25 . 
Table 3. Major fatty acid compositions of strain $1011 \mathrm{MAR} 3 \mathrm{C} 25^{\top}$ and its related species

Strains: 1, 1011 MAR3C25'; 2, Paracoccus saliphilus DSM 18447'; 3, 'Paracoccus siganidrum' DSM 26381'; 4, Paracoccus homiensis DSM $17862^{\top}$; 5 , Paracoccus aestuarii DSM $19484^{\top} ; 6$, Paracoccus alkanivorans LMG30882 ${ }^{\top}$. Data in columns $1-5$ are from this study and were obtained from cells grown under the same conditions. -, Not detected.

\begin{tabular}{|c|c|c|c|c|c|c|}
\hline Fatty acids & 1 & 2 & 3 & 4 & 5 & $6^{+}$ \\
\hline $\mathrm{C}_{17: 0}$ & $<1 \%$ & - & - & - & - & 1.2 \\
\hline $\mathrm{C}_{18: 0}$ & 7.90 & 8.74 & 4.51 & 7.86 & 6.30 & 5.7 \\
\hline $\mathrm{C}_{17: 1} \omega 8 \mathrm{c}$ & 1.41 & - & $<1$ & $<1$ & - & - \\
\hline $\mathrm{C}_{18: 1} \omega 7 c$-methyl & - & - & - & 6.81 & - & - \\
\hline $\mathrm{C}_{19: 0}$ cyclo $\omega 8 \mathrm{c}$ & 6.66 & 2.11 & 1.14 & - & - & 22.4 \\
\hline $\mathrm{C}_{10: 0} 3-\mathrm{OH}$ & 2.89 & 3.14 & 2.92 & 3.34 & 3.90 & 6.0 \\
\hline $\mathrm{C}_{18: 0} 3-\mathrm{OH}$ & - & - & - & 1.25 & - & - \\
\hline
\end{tabular}

*Summed feature 2 contains one or more of the following fatty acids: $\mathrm{C}_{12: 0}$ aldehyde/ $\mathrm{C}_{14: 0} 3-\mathrm{OH}$ and/or $\mathrm{C}_{16: 1}$ iso $\mathrm{I}$. Summed features are fatty acids that cannot be resolved reliably from another fatty acid using the chromatographic conditions chosen. The MIDI system groups these fatty acids together as one feature with a single percentage of the total.

†Data from Zhang et al. [41].

\section{DESCRIPTION OF PARACOCCUS ONUBENSIS SP. NOV.}

Paracoccus onubensis (o.nu'ben.sis, N.L. masc. adj. onubensis, pertaining to Onuba, the Roman name of Huelva, the province where the organism was first isolated).

Cells are facultatively anaerobic, non-motile, Gram-stainnegative and non-endospore-forming. They are $0.5-0.7 \mu \mathrm{m} \times 1.2-$ $1.8 \mu \mathrm{m}$ in diameter, grow in pairs or singly (Fig. S4). Colonies on marine agar are $0.5-1.3 \mathrm{~mm}$ in diameter, circular, convex, smooth and have entire margins. Good growth at $10-37^{\circ} \mathrm{C}$, optimal at $20-30^{\circ} \mathrm{C}$ and weak growth at 8 and $42^{\circ} \mathrm{C}$. Tolerates up to $12 \% \mathrm{NaCl}$, with optimum growth within 3-5\% (v/w) NaCl. Growth occurs at pH 5.0-9.0, with an optimum at pH 5.0-6.0. Catalase- and oxidase-positive. It grows heterotrophically with various carbon sources and chemoautotrophically with thiosulfate under aerobic conditions. D-Glucose, L-galactose, D-mannose, D-mannitol, $N$-acetylglucosamine, maltose, potassium gluconate, adipate, malate, citrate and phenylacetate can be utilized as carbon sources. Utilizes sodium nitrate, ammonium sulphate, sodium glutamate, casamino acids and peptone as sole nitrogen sources. Produces acid from D,L-arabinose, aesculin, $\mathrm{D}$-fructose, $\mathrm{D}$-fucose, D-galactose, D-glucose, D-mannose, D-ribose and D,L-xylose; weakly from D-adonitol, L-arabitol, L-fucose, glycerol, D-lyxose, maltose, melibiose, sucrose and trehalose. Negative for amygdalin, D-arabitol, arbutin, dulcitol, gentibiose, glycogen, inositol, inulin, lactose, melezitose, methyl a-D-glucopyranoside, methyl $\alpha$-D-mannopyranoside, methyl $\beta$-D-xylopyranoside, $N$-acetylglucosamine, potassium gluconate, potassium 2-ketogluconate, potassium 5-ketogluconate, raffinose, L-ramnose, salicin, D-sorbitol, L-sorbose, starch,
D-tagatose, turanose and xylitol. Reduces nitrate to nitrite. Hydrolyses aesculin and Tween 20, and does not hydrolyse DNA, casein or Tweens 40 and 80 . Produces alkaline phosphatase, esterase (C4), esterase lipase (C8), leucine arylamidase, valine arylamidase, cystine arylamidase, acid phosphatase, naphtholAS-BI-phosphohydrolase and a-glucosidase. Assimilates glucose, arabinose, mannose, mannitol, $\mathrm{N}$-acetyl-glucosamine, maltose, potassium gluconate, adipic acid, malate, trisodium citrate and phenylacetic acid, but does not assimilate capric acid. The most abundant fatty acid is $\mathrm{C}_{18: 1} \omega 7 \mathrm{c}$. Ubiquinone-10 is the major respiratory quinone. The polar lipids are diphosphatidylglycerol, phosphatidylcholine, phosphatidylglycerol and an unidentified aminolipid, an unidentified glycolipid and unidentified polar lipid.

The $\mathrm{G}+\mathrm{C}$ content of the type strain is $60.3 \mathrm{~mol} \%$. The type strain, 1011MAR3C25 ${ }^{\mathrm{T}}\left(=\mathrm{CECT} 9092^{\mathrm{T}}=\mathrm{LMG} 29414^{\mathrm{T}}\right)$, was isolated from white biofilms on the walls of the cave Gruta de las Maravillas, Aracena (Huelva, Spain).

\footnotetext{
Funding information

This study was supported by project 0483 PROBIOMA 5 _E, co-financed by the European Regional Development Fund within the framework of
} the Interreg V A Spain-Portugal program (POCTEP) 2014-2020.

\section{Acknowledgements}

We thank Isabel Galocha (IRNAS-CSIC) for technical assistance.

\section{Author contributions}

S.G.P., J.L.G.P., A.Z.M. and B.H.: data acquisition. V.L.: writing-original draft. C.S.J.: writing-review and editing.

Conflicts of interest

The authors declare that there are no conflicts of interest. 
References

1. Davis DH, Doudoroff M, Stanier RY, Mandel M. Proposal to reject the genus Hydrogenomonas: taxonomic implications. Int J Syst Bacteriol 1969;19:375-390.

2. Pujalte MJ, Lucena T, Ruvira MA, Arahal DR, Macián MA. The Family Rhodobacteraceae. Rosenberg E, DeLong E, Stackebrandt E, Lory S and Thompson F (eds). In: The Prokaryotes. Berlin, Heidelberg: Springer; 2014. pp. 439-512. https://doi.org/10.1007/978-3-64230197-1_377

3. Roh SW, Nam YD, Chang HW, Kim KH, Kim M-S, et al. Paracoccus aestuarii sp. nov., isolated from tidal flat sediment. Int J Syst Evol Microbiol 2009;59:790-794.

4. Dastager SG, Deepa CK, Li W-J, Tang S-K, Pandey A. Paracoccus niistensis sp. nov., isolated from forest soil, India. Antonie van Leeuwenhoek 2011;99:501-506.

5. Siller H, Rainey FA, Stackebrandt E, Winter J. Isolation and characterization of a new gram-negative, acetone-degrading, nitratereducing bacterium from soil, Paracoccus solventivorans sp. nov. Int J Syst Bacteriol 1996;46:1125-1130.

6. Wang Y, Tang SK, Lou K, Mao PH, Jin X, et al. Paracoccus saliphilus sp. nov., a halophilic bacterium isolated from a saline soil. Int J Syst Evol Microbiol 2009;59:1924-1928.

7. van Spanning RJM, Stouthamer AH, Baker SC, van Verseveld HW. Genus Paracoccus davis 1969, 384AL emend. Ludwig, Mittenhuber and Friedrich 1993, 366. Breener D, Krieg N, Staley J and Garrity G (eds). In: Bergey's Manual of Systematic Bacteriology. New York: Springer; 2005. pp. 197-204.

8. Dominguez-Moñino I, Jurado V, Hermosin B, Saiz-Jimenez C. Paracoccus cavernae sp. nov., isolated from a show cave. Int J Syst Evol Microbiol 2016;66:1-6.

9. Riquelme C, Hathaway JJM, Dapkevicius M, Miller AZ, Kooser A, et al. Actinobacterial diversity in volcanic caves and associated geomicrobiological interactions. Front Microbiol 2015;6:1342.

10. Lavoie KH, Winter AS, Read KJH, Hughes EM, Spilde MN, et al. Comparison of bacterial communities from lava cave microbial mats to overlying surface soils from Lava Beds National Monument, USA. PLOS ONE 2017;12:e0169339.

11. Marmur J. A procedure for the isolation of deoxyribonucleic acid from micro-organisms. J Mol Biol 1961;3:208-218.

12. Jurado V, Miller AZ, Alias-Villegas C, Laiz L, Saiz-Jimenez C. Rubrobacter bracarensis sp. nov., a novel member of the genus Rubrobacter isolated from a biodeteriorated monument. Syst Appl Microbiol 2012;35:306-309.

13. Yoon S-H, Ha S-M, Kwon S, Lim J, Kim Y. Introducing EzBioCloud: A taxonomically united database of $16 \mathrm{~S}$ rRNA and whole genome assemblies. Int J Syst Evol Microbiol 2017;67:1613-1617.

14. Campbell JH, O'Donoghue $P$, Campbell AG, Schwientek P, Sczyrba $A$, et al. UGA is an additional glycine codon in uncultured SR1 bacteria from the human microbiota. Proc Natl Acad Sci USA 2013;110:5540-5545.

15. Edgar RC. MUSCLE: multiple sequence alignment with high accuracy and high throughput. Nucleic Acids Res 2004;32:1792-1797.

16. Kumar S, Stecher G, Li M, Knyaz C, Tamura K. MEGA X: Molecular Evolutionary Genetics Analysis across computing platforms. Mol Biol Evol 2018;35:1547-1549.

17. Kimura M. A simple method for estimating evolutionary rate of base substitutions through comparative studies of nucleotide sequences. J Mol Evol 1980;16:111-120.

18. Nei M, Kumar S. Molecular Evolution and Phylogenetics. New York: Oxford University Press; 2000, pp. 1-333.

19. Bankevich A, Nurk S, Antipov D, Gurevich AA, Dvorkin M. SPAdes: a new genome assembly algorithm and its applications to singlecell sequencing. J Comput Biol 2012;19:455-477.

20. Bolger AM, Lohse M, Usadel B. Trimmomatic: a flexible trimmer for Illumina sequence data. Bioinformatics 2014;30:2114-2120.
21. Richter M, Rosselló-Móra R. Shifting the genomic gold standard for the prokaryotic species definition. Proc Natl Acad Sci USA 2009;106:19126-19131.

22. Lee I, Kim YO, Park SC, Chun J. OrthoANI: An improved algorithm and software for calculating average nucleotide identity. Int J Syst Evol Microbiol 2015;66:1100-1103

23. Urdiain M, López-López A, Gonzalo C, Busse HJ, Langer S, et al. Reclassification of Rhodobium marinum and Rhodobium pfennigii as Afifella marina gen. nov. comb. nov. and Afifella pfennigii comb. nov., a new genus of photoheterotrophic Alphaproteobacteria and emended descriptions of Rhodobium, Rhodobium orientis and Rhodobium gokarnense. Syst Appl Microbiol 2008;31:339-351.

24. Meier-Kolthoff JP, Auch AF, Klenk HP, Goker M. Genome sequencebased species delimitation with confidence intervals and improved distance functions. BMC Bioinformatics 2013;14:60.

25. Hyatt D, Chen GL, Locascio PF, Land ML, Larimer FW, et al. Prodigal: Prokaryotic gene recognition and translation initiation site identification. Bioinformatics 2010;11:119

26. Muñoz-Mérida A, Viguera E, Claros MG, Trelles O, Pérez-Pulido AJ. Sma3s: a three-step modular annotator for large sequence datasets. DNA Res 2014;21:341-353.

27. Consortium U. UniProt: a worldwide hub of protein knowledge. Nucleic Acids Res 2019;47:D506-D515.

28. Tambalo DD, Del Bel KL, Bustard DE, Greenwood PR, Steedman AE, et al. Regulation of flagellar, motility and chemotaxis genes in Rhizobium leguminosarum by the VisN/R-Rem cascade. Microbiology 2010;156:1673-1685.

29. Hucker GJ. A new modification and application of the gram stain. J Bacteriol 1921;6:395-397.

30. Halebian S, Harris B, Finegold SM, Rolfe RD. Rapid method that aids in distiguishing Gram-positive from Gram-negative anaerobic bacteria. J Clin Microbiol 1981;13:444-448.

31. Khan ST, Takaichi S, Harayama S. Paracoccus marinus sp. nov., an adonixanthin diglucoside-producing bacterium isolated from coastal seawater in Tokyo Bay. Int J Syst Evol Microbiol 2008;58:383-386.

32. Jones KL. Fresh isolates of actinomycetes in which the presence of sporogenous aerial mycelia is a fluctuating characteristic. J Bacteriol 1949;57:141-145

33. Barrow GI, Feltham RKA. Cowan and Steel's Manual for the Identification of Medical Bacteria. Cambridge: Cambridge University Press; 1965. pp. 21-45.

34. Lányi B. Classical and rapid identification methods for medically important bacteria. Colwell R and Grigorova R (eds). In: Methods in Microbiology, Vol. 19. London: Current Methods for Classification and Identification of Microorganisms, Academic Press; 1987. pp. $1-67$.

35. Wood AP, Kelly DP. Physiological characteristics of a new thermophilic obligately chemolithotrophic Thiobacillus species Thiobacillus tepidarius. Int J Syst Bacteriol 1985;35:434-437.

36. Boden R, Hutt LP, Rae AW. Reclassification of Thiobacillus aquaesulis (Wood \& Kelly, 1995) as Annwoodia aquaesulis gen. nov., comb. nov., transfer of Thiobacillus (Beijerinck, 1904) from the Hydrogenophilales to the Nitrosomonadales, proposal of Hydrogenophilalia class. nov. within the "Proteobacteria", and four new families within the orders Nitrosomonadales and Rhodocyclales. Int J Syst Evol Microbiol 2017;67:1191-1205.

37. Kelly DP, Wood AP. Autotrophic growth of Thiobacillus A2 on methanol. FEMS Microbiol Lett 1982;15:229-233.

38. Jurado V, Kroppenstedt RM, Saiz-Jimenez C, Klenk HP, Mouniée D, et al. Hoyosella altamirensis gen. nov., sp. nov., a new member of the order Actinomycetales isolated from a cave biofilm. Int J Syst Evol Microbiol 2009;59:3105-3110.

39. Liu Y, Q-y X, Hong K, Li L, Zhao YM, et al. Paracoccus siganidrum sp. nov., isolated from fish gastrointestinal tract. Anton Leeuw 2013;105:1133-1139. 
40. Kim BY, Weon HY, Yoo SH, Kwon SW, Cho YH, et al. Paracoccus homiensis sp. nov., isolated from a sea-sand sample. Int J Syst Evol Microbiol 2006;56:2387-2390.
41. Zhang YX, Li X, F-L L, S-C M, Zheng GD, et al. Paracoccus alkanivorans sp. nov., isolated from a deep well with oil reservoir water. Int J Syst Evol Microbiol 2020;70:2312-2317.

Five reasons to publish your next article with a Microbiology Society journal

1. The Microbiology Society is a not-for-profit organization.

2. We offer fast and rigorous peer review - average time to first decision is 4-6 weeks.

3. Our journals have a global readership with subscriptions held in research institutions around the world.

4. $80 \%$ of our authors rate our submission process as 'excellent' or 'very good'.

5. Your article will be published on an interactive journal platform with advanced metrics

Find out more and submit your article at microbiologyresearch.org. 